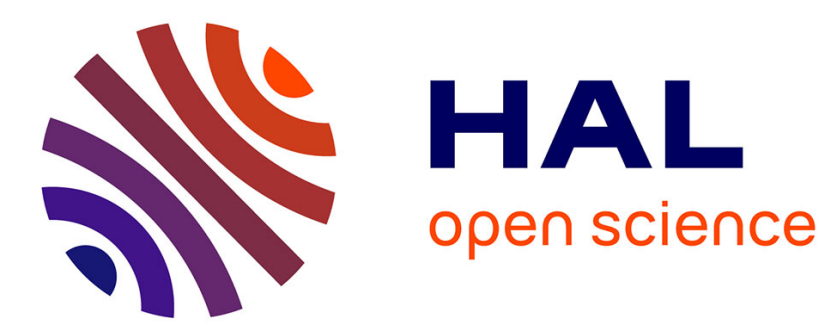

\title{
Implementing greenhouse gas trading in Europe: lessons from economic literature and international experiences
}

Catherine Boemare, Philippe Quirion

\section{To cite this version:}

Catherine Boemare, Philippe Quirion. Implementing greenhouse gas trading in Europe: lessons from economic literature and international experiences. Ecological Economics, 2002, 43 (2-3), pp.213-230. 10.1016/S0921-8009(02)00213-6 . halshs-00007264

\section{HAL Id: halshs-00007264 https://shs.hal.science/halshs-00007264}

Submitted on 16 Dec 2005

HAL is a multi-disciplinary open access archive for the deposit and dissemination of scientific research documents, whether they are published or not. The documents may come from teaching and research institutions in France or abroad, or from public or private research centers.
L'archive ouverte pluridisciplinaire HAL, est destinée au dépôt et à la diffusion de documents scientifiques de niveau recherche, publiés ou non, émanant des établissements d'enseignement et de recherche français ou étrangers, des laboratoires publics ou privés. 


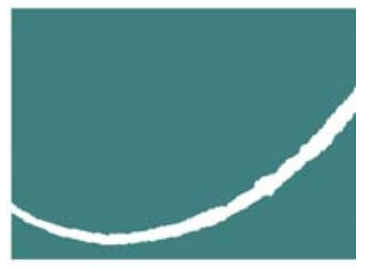

\section{C.I.R.E.D.}

CENTRE

INTERNATIONAL

DE RECHERCHE

SUR L'ENVIRONNEMENT

ET LE DÉVELOPPEMENT

\section{IMPLEMENTING GREENHOUSE GAS TRADING IN EUROPE: LESSONS FROM ECONOMIC LI- TERATURE AND INTERNATIONAL EXPERIEN- CES}

Catherine Boemare

Philippe Quirion

Published in 2002, Ecological Economics, 43, 213-230

C.I.R.E.D. UNITÉ MIXTE DE RECHERCHE

JARDIN TROPICAL

45 bis aVenue de la Belle Gabrielle

94736 NOGENT-SUR-MARNE CEDEX - FRANCE

TEL : (33-1) 0143947373

FAX : (33-1) 0143947370

http://www.centre-cired.fr 



\title{
IMPLEMENTING GREENHOUSE GAS TRADING IN EUROPE: LESSONS FROM ECONOMIC LIT- ERATURE AND INTERNATIONAL EXPERIENCES*
}

\author{
Catherine Boemare, \\ Philippe Quirion,
}

\begin{abstract}
The European Commission (2001a) has recently presented a directive proposal to the European Parliament and Council in order to implement a greenhouse gas emission trading scheme. If this proposal survives the policy process, it will create the most ambitious trading system ever implemented. However the legislative process is an opportunity for various interest groups to amend environmental policies which, as a result, generally deviate further from what economic literature proposes. A close look at implemented emission trading schemes, stressing their discrepancies with economic literature requests, is thus useful to increase the chances of forthcoming emission trading schemes to go through the political process.
\end{abstract}

We thus review ten emission trading systems, that are either implemented or at an advanced stage of the policy process. We draw attention to major points to be aware of when designing an emission trading system: sectoral and spatial coverage, permits allocation, temporal flexibility, trading organisation, monitoring, enforcement, compliance, and the harmonisation vs. subsidiarity issue. The aim is to evaluate how far experiences in emission trading move away from theory and why.

We then provide some lessons and recommendations on how to implement a greenhouse gas emission trading program in Europe. We identify some pros of the Commission proposal (spatial and sectoral coverage, temporal flexibility, trading organisation, compliance rules), some potential drawbacks (allocation rules, monitoring and enforcement) and items on which further guidance is

\footnotetext{
${ }^{*}$ The authors gratefully acknowledge contributions by two anonymous reviewers and the editors.
} 
needed (monitoring and allocation rules). Lastly, the European Commission should devote prominent attention to the U.S. $\mathrm{NO}_{\mathrm{X}}$ Ozone Transport Commission budget program, as the only example of integration between the federal and state levels.

\section{Keywords}

Emission trading, climate change policy, policy-making and implementation 


\section{Introduction}

Following the Bonn political agreement and the Marrakech Accords, reached respectively in July and November 2001, Japan, the European Union and several other European, Latin American, African and Asian countries have ratified the Kyoto Protocol. The Protocol will now enter into force if they are joined by Russia. Compliance with the first commitment period of the Protocol (2008-2012) will require a quick implementation of emission reduction measures, given the inertia of most emission sources. In the European Union, according to the European Climate Change Programme (European Commission, 2001b), there is a gap in the range of $6.6 \%$ and $8 \%$ between the effects of existing policies and measures and the Kyoto target. Given the failure of the European Council to agree on a European-wide tax scheme so far, the implementation of tradable permits is likely to be part of any cost-efficient combination of policies and measures able to reach the Kyoto target.

However, the failure of the European Commission tax proposals in the 1990s, in spite of their widespread support from environmental economists, recalls that even smart environmental policy proposals may perish during the policy process. More generally, as stressed by the positive political economy (Kehoane et al., 1998) due to the influence of various interest groups, very few environmental policies are implemented in their textbook forms.

A close look at implemented emission trading schemes, stressing their discrepancies with textbook requests, is thus useful to increase the chances of forthcoming emission trading schemes to go through the political process without being utterly watered down. First, any political entity proposing a trading scheme (generally the Ministry in charge of the environment, or the DG Environment of the European Commission) will receive various pressures from different lobbies on virtually any point of the proposal. Whereas refusing all lobby demands risks to lead to the rejection of the proposal, accepting any of them is generally neither feasible (some are contradictory) nor welfare improving. Knowledge of detailed features of existing schemes, including the design and negotiations of these features, may help these political entities to identify on what issues they may stand firm and on what issues they should compromise.

Second, interest groups lobbying consists largely in the dissemination and defence of arguments; knowledge of both economic literature and existing experience with emission trading is thus useful in the policy process. 
Such a systematic multilateral analysis has been lacking so far. Admittedly, a number of comparisons of emission trading schemes already exist. Schwarze and Zapfel (2000) provide a systematic comparison, but cover only two U.S. programs: RECLAIM and Acid Rain. Harrison and Radov (2002) analyse ten programmes, but only with respect to allocation. Unctad (1998) and Sonneborn (1999) overview progress made at that time in domestic, private and international trading schemes but were written before the design of most of the schemes we review. At last, Rosenzweig et al. (2002) review twelve recent programs but do not systematically compare their features. Furthermore their aim is descriptive and prospective - the development of the international greenhouse gas (GHG) market - rather than normative. In contrast we aim at advising policy-makers.

We thus review ten domestic and private emission trading systems, that are either implemented or at an advanced stage of the policy process. Information has been obtained from grey literature, academic sources and interviews. Five deal with $\mathrm{CO}_{2}$ : Denmark, the U.K., Norway, BP and Shell; two with $\mathrm{NO}_{\mathrm{X}}$ (U.S. OTC and the Netherlands); one with $\mathrm{SO}_{2}$ (U.S. Acid Rain), one with particulate matter (Chile) and one with both $\mathrm{SO}_{2}$ and $\mathrm{NO}_{\mathrm{X}}$ (RECLAIM). We thus leave out proposals that are not clearly enough defined yet, as well as several earlier or regional experiences in the United States, to prevent our survey to be too U.S.-focused. Earlier experiences in credit trading in the United States are reviewed in Stavins (2001). At last, we do not deal only with GHGs, since some lessons can be drawn from experience with other pollutants. We present together private and public trading schemes to allow a detailed comparison of their features, albeit these two types of systems obviously differ by the nature and motivations of the entity in charge of them.

Unlike most other comparisons mentioned above, we do not use the opposition between "cap-and-trade" and "baseline-and-credit" systems because a literature review reveals that such wordings are equivocal. Indeed, for UNCTAD (1998: 22), the specificity of a "baseline-and-credit" system is to be projectbased; on the contrary, in the way Boom and Nentjes (2002) define credit trading, "there is no need for abatement projects to create credits" but credits are expressed in unit of pollutant per unit of output; for Tietenberg (1999b: 8), a "credit" system "is typically denominated in terms of a pollutant flow such as tons/year"; for Rosenzweig et al. (2002: 2), the key distinction is that in a "baseline-and-credit" system, the seller does not necessarily have an emission cap. We thus avoid these terms but deal with these issues in sections 1.2 (optin) and 2 (output-based allocation). 
Although the idea of tradable permits is quite simple, their implementation involves several steps that may make one system essentially different from another. We thus point out major items to be aware of when designing an emission trading system. Section 1 deals with sectoral and spatial coverage. Sections 2 and 3 are about, respectively, permit allocation and temporal flexibility. Sections 4 presents trading organisation aspects, and section 5 discusses monitoring and enforcement. Lastly, section 6 draws some lessons on the harmonization vs. subsidiarity issue from the U.S. OTC $\mathrm{NO}_{\mathrm{x}}$ programme, the only example of integration between the federal and state levels.

For each item, we provide some recommendations on the implementation of a tradable permits system for GHGs in Europe.

Two tables at the end of the paper gather the core information on the ten systems studied, as well as on the EU trading directive proposal.

\section{Sectoral and spatial coverage}

\section{I.1. Theoretical requirements}

Standard theory suggests that providing, first, damages do not depend on localisation of emissions and, second, administrative and monitoring costs are not disproportionate, as many emitters as possible should be covered by the permit scheme, for two reasons.

First, a large number of participants is required to benefit from significant abatement cost differences among firms.

Second, it lowers the risk of market power on the permit market. Market power involves the ability of participants to manipulate prices strategically either as a monopolistic seller or a monopsonistic buyer (Hahn, 1984). This behaviour has two detrimental effects. First, it reduces the volume of transactions, lessening the cost-effectiveness of the system. Second, as shown by Misiolek and Elder (1989), the combination of market power on the permit market and on the good market may allow some firms to dry up the permit market in order to prevent the entry of new firms or to push existing ones out of the market. For this to happen, participants in the permit scheme have to operate on the same good market. 
For $\mathrm{CO}_{2}$ emissions from fossil fuel burning, two levels of control are available: upstream (at the level of the producers and importers of fossil fuels, who would then raise their prices) and downstream (at the level of the fossil fuel consumer, i.e., the $\mathrm{CO}_{2}$ emitter). In a world with no distortion (apart from the environmental externality), the former approach should be preferred, since the latter does not allow to control diffuse sources (households and small firms) without raising transaction costs to a very high level. However, one can argue that diffuse sources pay typically higher pre-existing taxes on fossil fuels than large emitters, hence a downstream system, targeting the latter, may be prefer$a_{b l e}{ }^{1}$. Furthermore if energy markets are imperfect, permit cost may be passed on unevenly to various types of consumers, lessening the superiority of an upstream scheme.

For other pollutants than GHGs, location does matter and the threat of "hot spots", i.e., local concentration of pollution, may be a rationale for limiting spatial coverage. Emission trading may increase the threat of hot spots in two main ways. First, trades may create unacceptably high local concentrations near sources that have acquired permits as an alternative to further control. Second, permits may allow the long range transport of emissions to increase, thereby increasing deposition problems (Tietenberg, 1999b).

Two tools have been proposed to adapt emission trading to these problems. First, a substitute to the limitation of the spatial coverage is to define "exchange rates" between geographical zones. Second, air quality goals or deposition targets at certain locations can be approached by the creation of transferable ambient permits or deposition permits (Ermoliev et al., 2000). However administrative and transaction costs may well be very high, which provides a rationale for a reduction in spatial coverage.

A reduction in sectoral coverage may also be sound in some cases, in particular when pre-existing energy taxes differ from one sector to another, thus preventing permit trading from equalising social marginal abatement costs among sectors (Babiker et al., 2001).

\section{2 How far experiences in emission trading move away from theory and why}

\footnotetext{
${ }^{1}$ Zhang (1998) also argues that only a downstream system provides an incentive for energy endusers to develop carbon disposal technologies; however, even leaving aside the shortcomings of these technologies, in an upstream system, credits could be created for disposal just as they should be given for petroleum used as a feedstock.
} 


\section{Spatial coverage}

To our knowledge, markets for tradeable ambient permits do not exist, nor do systems of exchange rates between geographical zones. Location is dealt with by reducing spatial coverage (RECLAIM), by imposing restrictions on trading ( $\mathrm{NO}_{\mathrm{X}}$ OTC; see Tietenberg, 1998), or by "regulatory tiering" ( $\mathrm{SO}_{2}$ in the U.S.; see Tietenberg, 2001), which combines a trading with a non-trading instrument, the latter protecting against harmful spatial clustering of emissions. Spatial coverage is also reduced because upwind states or regions are reluctant to cut their emissions if damages they cause occur mainly in downwind states or regions $\left(\mathrm{NO}_{\mathrm{X}}\right.$ OTC; cf. Farrell, 2001).

Such concerns are important concerning ozone or acid rains, but much less when addressing climate change where the GHG accumulation in the atmosphere determines the global warming potential. Note, however, that reducing $\mathrm{CO}_{2}$ emissions from fossil fuels usually leads to a reduction in local pollutants; hence localisation of emissions does matter, although indirectly.

The comparison of large- (Acid Rain), medium- (OTC budget) and small-scale (RECLAIM) existing schemes indicates that the larger the coverage, the smaller the price volatility (Farrell, 2002; Ellerman, 2001).

\section{Sectoral coverage}

In most cases, the regulators have chosen not to include as many emitters as possible, at least in a first phase, possibly to avoid facing too many oppositions at a time. Sectoral coverage has sometimes been reduced to one sector at the beginning of the system in order to reach the simplest system possible (Denmark).

For this reason, with the exception of the Norwegian project, a downstream approach has been preferred over an upstream one (U.K., Denmark, BP, Shell).

Acid Rain and OTC budget have been implemented in two phases whereas the others have not. In the Acid Rain program, large sources with relatively high $\mathrm{SO}_{2}$ emissions were regulated first in Phase I which lasted from 1995 to 2000. Phase II started in 2000 and includes most other significant sources. Because the electric utility industry is highly interconnected, sources in Phase I can easily shift their load (and emissions) to unaffected sources which would not be covered until Phase II. This load shifting capability has made implementing a phased approach difficult (Environmental Law Institute, 1997). 
Experiences show that although the pollutants covered among the emission trading schemes are different, electricity generating units are the most often affected sources (Acid Rain, OTC budget, Denmark). Notable exceptions are the U.K. scheme - Although electricity generators might opt-in on a projectby-project basis - and the RECLAIM one for $\mathrm{SO}_{2}-\mathrm{NO}_{\mathrm{X}}$ emissions from electricity generation are covered. This is due to social reasons in the U.K.: the government did not want the electricity bill of low-budget households to go up, fuel poverty being a hot issue in this country.

\section{Phase-in}

To alleviate the difficulty in implementing a large system at once, a phased approach can expand coverage so as to get the most comprehensive system as possible but a phased coverage of sources within an industry may create a perverse incentive to shift production to non regulated sources (e.g. smaller units). This problem could be addressed by an output based allocation, but with possible other perverse side effects (cf. 2.1 below and Fischer, 2001). Note that a phased coverage of industries does not raise such concern.

\section{Opt-in}

Some programs include provisions for firms to voluntarily participate (opt-in) either as a permanent part of the program, receiving an annual allocation of allowances, or on a project-by-project basis. The Acid Rain program allows two provisions for permanent opt-in. The first type of opt-in allowed utility sources that would normally not be covered until Phase II (starting in 2000) to participate in Phase I (1995-2000). In addition, the program provides for nonutility industries with $\mathrm{SO}_{2}$ emissions to opt into the regulatory system. This opt-in program allows these important sources of emissions to participate in the program, which otherwise would not cover them. The EPA (Environmental Protection Agency) has promulgated opt-in rules for industrial combustion sources, which emit $14 \%$ of all $\mathrm{SO}_{2}$.

Any opt-in source has to have a definable baseline and accurate emissions monitoring to guarantee that any further reductions they make contribute to the environmental goals. The opt-in source must demonstrate its baseline emissions and an adequate monitoring plan (Environmental Law Institute, 1997).

Indeed, sources have an interest in opting in if they can cheaply reduce emissions and derive economics benefits from selling their excess allowances. This raises the risk that firm opt in only if they can benefit from an over-estimated baseline - "hot air" in the climate negotiations lingo. There is thus an obvious trade-off between administrative and monitoring costs, on the one hand, and 
environmental integrity on the other hand. In the Acid Rain case, Montero (2000) explains that a large number of non-affected units opted in because their unrestricted emissions were below their permit allocation - they had received excess permits. The author develops a theoretical model of optimal permit allocation to opt-in firms, but how to best implement such a model in practice remains a topic for future research.

\section{I.3 Lessons for the European GHG trading scheme}

The European Commission proposal provides a wide spatial and sectoral coverage, even if other gases than $\mathrm{CO}_{2}$ and $\mathrm{CO}_{2}$ from chemical industry processes are not covered. These emissions are likely to be phased in later. The former exemption is motivated by monitoring difficulties, which should not be underestimated, although the Norwegian proposal includes some of them. The latter is motivated by the number of sources and the resulting administrative costs, but a more likely explanation is the will to soften opposition from the German chemical industry, which already rejects the directive because of the resulting increase in energy costs. A significantly wider coverage could have been provided only by an upstream system, which has been excluded by the Commission at the beginning of the process. The reason was again political: an upstream scheme would have too much looked like the carbon tax rejected in the nineties.

The coverage could have been narrowed a lot by the opt-out provision that was present in previous drafts of the proposal. It allowed a state to exclude some sectors from the system, provided that they were regulated by another instrument, such as a voluntary agreement. Such a provision, which is still pushed for by some industries and Member States, may harm a lot the efficiency of the system.

Perhaps for the sake of symmetry, the opt-in provision has also been dropped in the final proposal. The possibility to develop an opt-in scheme that induces a significant number of firms to take commitments without weakening the environmental ambition and boosting administrative costs is unlikely, in the light of the Acid rain experience. However, the Commission (2001b) intends to introduce another directive allowing opt-in on a project-by-project basis, which would create the same problems. 


\section{Permits allocation}

\section{II.1. Theoretical requirements}

From an economic point of view, three methods of allocating permits have to be distinguished: auction, criteria exogenous for firms receiving the permits, and output-based allocation.

- when allowances are auctioned, the permits are allocated to the highest bidders. Various allocation methods exist (see Klemperer, 1999, for a general survey or Cramton and Kerr, 2002, for auctioning applied to tradable permits).

- the most common exogenous criteria are grandfathering, i.e., a share of historical emissions, and benchmarking, i.e., a proportion of historical production. With purely exogenous criteria, new entrants have to buy their permits from existing sources and a firm continues to receive permits even if its plants shut down.

- with an "output-based" or "performance standard" allocation, firms receive an amount of permits proportional to their current production ( $x$ permits per $\mathrm{kWh}$ for power plants, $y$ permits per ton of aluminium...). Of course, since no sole indicator of production exists, the total amount of permits has first to be divided between sectors, except when a single sector is covered. Such an allocation method is equivalent to "specific" or "relative" permits (or credits), i.e., expressed in relative terms (e.g., one ton of $\mathrm{CO}_{2}$ per $\mathrm{kWh}$ ).

General equilibrium modelling has shown that the most cost-efficient way to allocate permits is to auction them and to use the revenue to cut pre-existing distortionary taxes (e.g. Goulder et al., 1999; Fullerton and Metcalf, 2001). Indeed grandfathered and auctioned permits, like any instrument that allows firms to reach part of their target by reducing their production, raise product prices above the marginal cost of production, generating a scarcity rent. With grandfathering, this rent is captured by regulated firms, which is socially inefficient when public funds are raised through distortionary taxes. Auctioning socialises this scarcity rent and allows to use it to cut pre-existing taxes or to produce public goods. According to the "strong double-dividend" hypothesis (Goulder, 1995), such policy would even increase welfare and employment. Although this hypothesis is controversial, the superiority of auctioning over grandfathering (the "weak double dividend") is not. 
Furthermore, grandfathering reduces the incentive for regulated firms to develop environmental innovations, as compared to auctioning (Milliman and Prince, 1989). This is because environmental innovations reduce the value of the permits, thus the wealth of permits-holders.

Third, grandfathering may create a bias against new firms entering product market, since existing firms get their permits free while new firms must buy them (Howe, 1994). Such a problem may arise if the capital market is imperfect and/or if existing firms benefit from market power on the permits markets. In both cases, these firms may be able to use their permits to drive their potential competitors out of the market.

At last, before the beginning of the system, grandfathering can increase pollution if sources are aware that larger current emissions will result in larger future permit allocations. This problem can be circumvented by basing the initial allocation, not on actual emissions, but on past emissions, or on the commandand-control authorised emissions, as it has been done in the earlier stages of permit systems in the United States (Tietenberg, 1999a).

Output-based allocation does not suffer from the first shortcoming: it does not create scarcity rents since it provides no incentive to raise the price-cost margin. Nor does it suffer from the third weakness: new entrants receive the same number of permits as existing firms. However, the allocation of permits acts as a subsidy to production. Therefore, it prevents to fully mobilise inter-sectoral substitutions in the overall reduction in emissions. For instance, an outputbased $\mathrm{CO}_{2}$ permits scheme would provide an incentive to reduce $\mathrm{CO}_{2}$ emissions per ton of concrete produced, but hardly to substitute wood for concrete in buildings. Furthermore, the definition of "output" raises complex problems (Fischer, 2001).

The main economic advantage of an output-based allocation over the two others is that it reduces drastically the incentive to relocate polluting activities in "pollution havens". Indeed, if a polluting firm closes, it receives no permits anymore. On the contrary, with pure grandfathering, a firm can close its plants in the regulated country, build a new plant abroad and still benefit from grandfathered permits.

Edwards and Hutton (2001) general equilibrium simulations indicate that such an output-based $\mathrm{CO}_{2}$ permits scheme could allow much of the potential "double dividend" to be realised, though an auction system would still be preferable. On the other hand, Burtraw et al. (2001) partial equilibrium simulations of the electricity generation sector in the U.S. suggest that output-based allo- 
cation of $\mathrm{CO}_{2}$ permits would imply roughly the same cost than grandfathering, and about twice that of auctioning.

\section{II.2. How far experiences in emission trading move away from theory and why}

Most experiences in emission trading have used grandfathering or benchmarking (Acid rain, RECLAIM, Chile, U.K., BP, Shell), sometimes with special provisions for new entrants: auctioning (Acid rain) or free distribution according to criteria still to be defined (Denmark). Exceptions are the OTC budget that lets firms decide between grandfathering and an output-based allocation, the Dutch $\mathrm{NO}_{\mathrm{X}}$ (output-based allocation) and the proposal of the Norwegian quota commission, a majority of whom favours selling the allowances. Implementation of the latter system is not decided yet.

The choice of grandfathering in most systems is a direct consequence of the political influence of regulated firms in the policy process (Kehoane et al., 1998). Indeed, a lesson from positive political economy is that firms which risk an important loss are more likely to incur the costs of lobbying than households or firms which could benefit from a reduction in pre-existing taxes - even if they outnumber the former ${ }^{2}$.

A politically interesting feature of the output-based allocation is that it can be based on existing performance standard, like in the Dutch system, which likely increases its acceptability among firms and the administration. Furthermore, an output-based allocation is more acceptable to regulated firms than auctioning since it is revenue-neutral.

\section{II.3. Lessons for the European GHG trading scheme}

The proposal let each Member State design a national allocation plan which has to respect a number of criteria, related in particular to the EU burden sharing agreement and competition rules, and which will be reviewed by the Commission. In addition permits have to be distributed free of charge in the first period (2005-2007), while the allocation method for next periods is to be decided later on. According to the directive proposal, the plan shall "contain

${ }^{2}$ According to an anonymous referee, this idea can be traced back to Machiavelli. 
information on the manner in which new entrants will be able to begin participation", and the explanatory memorandum adds that Member States should "ensure that new entrants have adequate access to allowances" without further precision. However, in its statement on the Danish emission trading system, the European Commission obliged Denmark to provide new entrants with permits in the same conditions than existing firms, which constitutes a step towards an output-based allocation. Furthermore a "new entrant" is not defined: does it apply only to a company not previously producing in the Member State? To a new site? A new installation? A capacity extension of an existing installation? Hence the degree of freedom let to Member States for choosing among possible free-of-charge allocation criteria in the first period remains unclear.

The allocation issue is arguably the aspect of the proposal which is most open to criticism. Let's in turn examine three possible rationales for harmonising allocation: two conceptions of competitive distortions and carbon leakage. Van der Laan and Nentjes (2001) as well as Woerdman (2001) note that there are two interpretations of the competitive distortion concept: first, as an inefficiency in allocation of resources and, second, as an inequity of firm's starting conditions. From the efficiency perspective, there is no competitive distortion and thus no need for harmonisation if some countries distribute permits free of charge according to an exogenous criterion, and others auction them. Indeed, even grandfathered permits have an opportunity cost; see also Zhang (1999a). On the contrary, there is a rationale for preventing (or harmonising) outputbased allocation since it constitutes an output subsidy, albeit combined with a tax on pollution. The directive proposal is thus inconsistent with the efficiency interpretation of the competitive distortion argument.

In the equity interpretation of competitive distortions, the focus is on equity among firm-owners in different countries, which incidentally seems an odd policy goal since the ownership of firms to be regulated by the directive is more and more trans-national. Anyhow, a generalisation of free allocation does not makes much sense, because it must be stressed that not all the permits have to be grandfathered to compensate existing firms: several studies show that the grandfathering of all permits is likely to overcompensate the regulated industry. Bovenberg and Goulder (2000) as well as the U.S. Congressional budget office (2000) have demonstrated that the complete grandfathering of $\mathrm{CO}_{2}$ upstream permits in the U.S. would let fossil fuel firms better off, and not worse off. Indeed, the gain from the scarcity rent would be much greater than the profit loss due to the decline in production. According to Burtraw et al. (2001), the same is true for downstream $\mathrm{CO}_{2}$ permits in the U.S. electricity 
generation sector. At last, simulations by Hourcade et al. (2002) exhibit the same conclusions for the European iron and steel sector.

If, now, one is afraid of "carbon leakage" towards unregulated areas, pure grandfathering or benchmarking, if capital is perfectly mobile, does not perform better than auctioning ${ }^{3}$.

We thus have to rely on political economy reasons to explain allocation choices in the directive proposal. For energy-intensive lobbies, two sequential decisions may impact their profit: the adoption of the directive and the acceptance the approval of national allocation plans. For the Commission, prohibiting auctioning in the directive reduces the risks of seeing these lobbies opposing the directive just to prevent National allocation plans from relying heavily on auctioning.

For the Commission, this is probably a good way to reduce the risk of rejection of the proposal. A more ambitious and risky strategy would be to try to mobilise potential winners from auctioning combined to existing tax cuts, following the "double-dividend" strategy that allowed ecological tax reforms in Scandinavian countries. However, this strategy failed in the European Community in the early nineties and it is not more likely to succeed now. Another ambitious and risky strategy, following Kopp et al. (1999), would be to distribute revenues from auctioning to all citizens as a basic income in order to increase public support for emission mitigation, but distributing revenues to citizens is not part of European institutions competences.

All in all, the choices of the European Commission as regards allocation reflect political economy constraints much more than an application of insights from economic theory.

\footnotetext{
${ }^{3}$ Auctioning permits in the sheltered sectors and allocating them according to production in exposed sectors, as the Dutch Vogtländer commission on $\mathrm{CO}_{2}$ trade recommends, could have made sense. However the European Union as a whole is much less open than the Netherlands, and energy-intensive sectors are not among the most exposed to international competition, as shown by Fouquin et al. (2001). Simulations by Hourcade et al. (2002) conclude that the implementation of the proposed directive would not create a significant carbon leakage problem.
} 


\section{Temporal flexibility}

\section{III.1 Theoretical requirements}

Standard theory suggests that as long as there is no risk of "temporal hot spots", a fully cost-effective tradable permit system must have full temporal flexibility, implying that allowances can be both borrowed and banked (Rubin, 1996). In general banking encourages firms to make early investments by allowing them to either use or sell allowances not needed for compliance during the current year. Banking of allowances provides sources with significant additional flexibility in compliance investment and decision-making.

The key concern with banking involves the potential for creating "temporal hot spots". Complete freedom on temporal offers the possibility for emissions to be concentrated in time. Since clustered emissions can cause more danger than dispersed emissions, regulators have chosen to put restrictions on the temporal use of permits despite the cost-effectiveness penalty that extracts (Tietenberg, 1999b).

Another concern lies in the fact that the accumulation of a large bank of allowances could make rapid implementation of future emissions reductions more difficult.

Borrowing gives flexibility by allowing firms to delay investments until such time as they may be optimal from the firm's perspective. However, it raises two concerns. First, borrowing, especially if unlimited, triggers the possibility to delay emission reduction indefinitely. Second, pending the adoption of future commitments, a source may have an incentive to rely heavily on borrowing to artificially raise its future compliance cost curve and obtain softer future targets.

\section{III.2 How far experiences move away from theory and why}

\section{III.2.1 Allowance reference period}

The allowance reference period can be daily, seasonal or annual. It is related to the perceived damage pattern: when marginal environmental damage is thought to be relatively constant over one or several years, as for global warm- 
ing or acidification by $\mathrm{SO}_{2}$, the reference period is at least annual. For ozone or particulates, because pollution peaks mater, the reference period is daily (Chile) or seasonal (five months in OTC budget).

\section{III.2.2 Banking}

Most of the emission trading programs allow banking, the Netherlands, RECLAIM and Chile being exceptions. Sometimes it is restricted because of health considerations (OTC budget). There has been heavy use of banking in the U.S. Acid Rain Program, which has led to early reductions and substantially lowered overall costs of compliance. Banking is especially significant for industries in which major capital expenditures must be made, as it allows individual sources flexibility in the timing of such major investments.

The argument against banking by which banked allowances could be used over a short term period to increase emissions with a detrimental effect on environment, may be significant for $\mathrm{SO}_{2}$ or $\mathrm{NO}_{\mathrm{X}}$ but is not for GHGs.

Another concern by which the accumulation of a large bank of allowances could threaten futures GHG reductions can be addressed by giving allowances a long but limited life or by limiting the overall possible amount of banked allowances. It would prevent the possibility that a large allowance bank may build up and affect the government's ability to increase or decrease allowance allocating according to future internationally negotiated limits. The Environmental Law Institute (1997) report proposes a long life such as 20 years to allow sources to capture all the benefits of banking, while allowing the government increased flexibility; in addition, the size of any future reduction could also be adjusted to reflect the size of the allowance bank.

\section{III.2.3 Borrowing}

Borrowing is not explicitly allowed in any emission trading experiences because of ensuing difficulties in resolving environmental problems ${ }^{4}$. However, restoration of "excess tons" in subsequent periods, which is de facto borrowing, is a part of the compliance system in the OTC $\mathrm{NO}_{\mathrm{X}}$ (cf. 5.2 below).

\footnotetext{
${ }^{4}$ According to UNCTAD (1998: 18) New Zealand fisheries license trading (not reviewed here) allows borrowing up to $10 \%$ of the annual quota, but this provision "may be repealed, as borrowing has proven administratively complex and has caused enforcement problems".
} 


\section{III.3 Lessons for the European GHG trading scheme}

Because the European directive proposal aims at helping the E.U. to comply with the Kyoto Protocol, it is useful to recall the temporal flexibility provisions of the Protocol and subsequent texts. The Protocol allows banking (except, since the Marrakech Accords, for sinks credits), which may encourage early reductions beyond the Kyoto target. For the reasons mentioned above, borrowing, as a flexibility mechanism, has not been allowed by the Protocol. However, according to the Bonn political agreement, the main provision for non-compliance is the deduction of 1.3 times the excess emissions from a Party's first commitment period assigned amount, to be applied to the assigned amount of the second commitment period. This is economically borrowing ${ }^{5}$, but is politically very different since a Party in such a situation will be declared in non-compliance and undergo other consequences: submission of a compliance action plan, suspension of eligibility to transfer allowances via emission trading or joint implementation.

The directive proposal allows for the banking of allowances but not for the borrowing. Both provisions seem sound, the former because there is no risk of "temporal hot spot" in the context of climate change, the latter for all the reasons mentioned above. The resulting loss of cost-effectiveness in eliminating borrowing is a reasonable price to pay for easing enforcement and compliance.

\section{Trading organisation}

\section{IV.1Theoretical requirements}

If all participants emissions are capped, and without monitoring or enforcement problem (cf. section 5 below) there is no reason to require a governmental approval for trades.

On the contrary, requiring trades to be centralised by a clearing-house or broker makes sense to prevent market power, improve price information and market efficiency; such an institution would play the role of Walras "secrétaire de marché". However if the market is big and atomistic enough a single price is likely to emerge.

\footnotetext{
${ }^{5}$ The interest rate is $30 \%$ over the five-years period hence $5 \%$ per year.
} 
At last, compulsory registration of trades is a useful management tool because it creates an open, public process for allowance recordation which helps ensure compliance with the law. Coupled with the penalty provisions a registry works well for compliance purposes (Environmental Law Institute, 1997).

\section{IV.2 How far experiences move away from theory and why}

All programs allow direct bilateral trade, except BP and Shell's in which transactions have to be made through a central broker, and Chile in which an administrative approval is required.

All implemented emission trading systems include the registration of transfers (Acid Rain, OTC budget, RECLAIM). A registry set up by the organism who has the institutional governance records the companies' allowances accounts (except in the Danish case).

International experiences speak for simplicity: bilateral trade without prior government approval favours trading and lowers transaction $\operatorname{costs}^{6}$ but mandatory registration is needed to assess country compliance with the Kyoto commitment.

\section{IV.3 Lessons for the European GHG trading scheme}

The EU directive proposal sticks to usual practices by allowing bilateral transactions without government approval but with mandatory registration, which is neither surprising nor unsound.

\section{Monitoring and enforcement}

\section{V.1. Theoretical requirements}

The enforcement of permit system depends on the technical ability to detect violations and the legal ability to deal with them once detected, thus to deter them.

\footnotetext{
${ }^{6}$ Most earlier U.S. credit trading programs (not reviewed here) required government approval and, according to UNCTAD (1998: 19), have "not achieved significant economic or environmental benefits" because of induced transaction costs.
} 
Direct continuous monitoring of emissions has been an important factor is the success of the Acid Rain program but others techniques are available for estimating the emissions flow, such as, for $\mathrm{CO}_{2}$, calculation using activity data, emission factors and oxidation factors. A second requirement is the legal authority to deal with non compliance including effective sanctions. A guideline can be set up: the smaller the probability of control is, the higher the non compliance penalty should be.

The last point is the liability rule, i.e., does a permits remain valid when its issuer turns out to be in non-compliance? The answer is yes in a "seller liability" regime and no in a "buyer liability" one, but numerous other rules exist ${ }^{7}$. Pure seller liability should be avoided if the compliance regime is weak, since it can spur over-selling (Zhang, 1999b). If the compliance regime is strong, pure seller liability minimises transaction costs.

\section{V.2 How far experiences move away from theory and why}

\section{V.1.1. Monitoring}

One of the reasons why the Acid Rain program has been successful is the high integrity of the allowance currency, due to the requirement that utilities install continuous emissions monitoring devices to accurately measure actual emissions (Environmental Law Institute, 1997).

Several programs require continuous emissions monitoring by sources (Acid Rain, OTC budget, RECLAIM).

Reporting is a key compliance mechanism and covers both emissions monitoring results and emission trading activity. On a national level, many countries require monthly reporting of emission data. Continuous emissions monitoring technology allows reporting as often as every 15 minutes. U.S. domestic trading systems require reporting of emission trading activity to a government registry which is open to the public and may be available on the world wide web (Unctad, 1998).

\footnotetext{
${ }^{7}$ Haites and Missfeldt (2000) analyse these rules in the context of the Kyoto Protocol.
} 


\section{V.1.2. Penalties}

Acid Rain, RECLAIM, Denmark, Chile, U.K. set penalties for noncompliance, but at very different levels: respectively $\$ 2000 /$ ton $\mathrm{SO}_{2}$, $\$ 500$ per day and $\$ 6$ per ton $\mathrm{CO}_{2}$ for the first three. The OTC budget let states defines penalties; most of them combine a financial fine with a deduction of allowances from the subsequent year. Compliance appears to be positively correlated both to the level and to the automatic nature of penalties (Stranlund et al., 2002). In BP, there is no penalty whereas in Shell there is a fine equal to three times the average fourth quarter price for each permit short fall.

\section{V.1.3. Liability}

All the systems we have studied feature seller liability.

\section{V.3 Lessons for the European GHG trading scheme}

High quality monitoring is essential to assure effectiveness of both compliance and trading systems. The Commission decision to start with the sole $\mathrm{CO}_{2}$ reflects the importance given to monitoring. However it allows for calculation using activity data, emission factor and oxidation factor, which is not without problems. The accuracy of current national inventories based on this method falls far short of what is needed for a trading scheme, but further guidance will be provided at the EU level by an ongoing commission.

The main difficulty is likely to stem from the international character of EU policy. Implementation of EU directives, unlike that of national policies, is a two-stage process (Glachant, 2001). The directive has first to be transposed in the Member States' legislation and then put into practice by national administrations. This threatens effective implementation since in addition to the classical risk of non-compliance by the polluters, the states may fail to transpose the directive or to apply correctly its provisions.

Compliance penalties seem to be set at a sufficiently high level: $50 € / t \mathrm{CO}_{2}$ in the first period, 100 afterwards, or twice the average market price, whichever is the higher. In addition restoration of excess tons is required in the following year. Seller liability is thus a judicious choice if the directive is properly enforced by Member States. Otherwise, a joint liability to the buyer and the seller could be sensible. 


\section{Harmonisation versus subsidiarity}

In the Green paper on emission trading issued by the European Commission (2000) to prepare the directive, most open questions were related to the "harmonisation vs. subsidiarity" issue: what should be set at the European level and what should be left for Member States to decide? Three features were of particular concern: sectoral coverage, compliance regime and allowance allocation.

\section{VI.1. Theoretical requirements}

A basic theoretical requirement is to try to equalise costs and benefits in each country. Since the benefit from cutting emissions is the same in whatever country the reduction takes place, and because tradable permits allow to equalise marginal abatement costs despite national circumstances ${ }^{8}$, theory calls for a high degree of harmonisation of sectoral coverage and compliance regime. The picture is more complex on allowance allocation: it has a large impact on revenue distribution, which is a Member State competence, but also possibly efficiency consequences (cf. 2.1 above).

\section{VI.2. The experience of the U.S. NOx OTC budget pro- gram}

The OTC program in the United States gives the only example of integration between federal and state levels. The program is under U.S. Environmental Protection Agency (EPA) guidance. Eleven north-eastern states, the district of Columbia and Northern Virginia implemented a trading system in 1999 to reduce compliance costs associated with the OTC (Ozone Transport Commission) regulations of the 1990 Amendments of the Clean Air Act (Farrell et al., 1999).

\footnotetext{
${ }^{8}$ This is true only as long as pre-existing differences in the regulatory and fiscal frameworks does not create false gains from trade, as stressed by Babiker et al. (2001). This calls for implanting the directive proposal on harmonising minimum excise duties across Member States, but it is unlikely that increasing the degree of freedom of Member States in the trading system would help to solve the problem.
} 
EPA distributes $\mathrm{NO}_{\mathrm{x}}$ allowances to each state based on state wide emissions inventories and states are free to determine the allocation procedure to sources. Each state has to identify its budget sources.

How did the states identify their budget sources? In 1994, the states under the OTC program (except Virginia) have signed a Memorandum of Understanding (MOU). They agreed they would implement reasonably available control technologies (RACT) on major stationary sources of $\mathrm{NO}_{\mathrm{X}}$ in phase I (before the implementation of emission trading which only begin in phase II in 1999) and agreed to a phased approach for additional controls, beyond RACT for power plants and other large fuel combustion sources (phase II and III). The MOU establishes an emission trading system to reduce the costs of compliance with the control requirements under Phase II (which began on May 1, 1999) and Phase III (beginning on May 1, 2003).

Although states have to identify their budget sources, the MOU provides guidance: the budget sources include a core group of electric generating units with a rated electrical output of $15 \mathrm{MW}$ or greater, and fossil fuel-fired boilers or indirect heat exchangers with a maximum rated heat input capacity of 250 $\mathrm{mmBtu} /$ hour or more. Aside from these requisite budget sources, states also had the option of including other source categories (e.g. cement plants) in the program. Additional stationary sources of $\mathrm{NO}_{\mathrm{X}}$ emissions designated as eligible by the state may choose to opt-in on an individual basis. In fact, the OTC seasonal budget was developed through a uniform process across all states.

How did the states allocate allowances ? Under the MOU a 'model' trading rule has been developed for states in the OTC to use as a template in the development of their own regulations. While the model rule was developed as guidance for state regulatory development, the OTC is state-operated and decentralised by design. States therefore had the option of 'tailoring' individual program elements such as allocation methodology to fit state-defined criteria.

The number of allowances distributed in each state is calculated as a percentage of total (actual or estimated) 1990 emissions or the equivalent as a "performance standard" (which is basically an output-based allocation). A source may choose which standard applies to it, and the state environmental agency then allocates allowances according to this standard.

- The states are responsible for ensuring that sources are in compliance with all requirements of the program (monitoring and reporting actual emissions and compliance demonstration process). 
- EPA is responsible for reviewing and approving each state's regulation into a State Implementation Plan.

- EPA is responsible for developing and operating an adequate trading registration.

\section{VI.3. Lessons for the European GHG trading scheme}

OTC budget has common rules concerning affected sectors, compliance provisions and (partly) allocation criteria. A core of participants is defined at the federal level. The first three years of the trading program (1999-2001) seem to draw a successful picture: emissions have decreased faster than required, noncompliance has been marginal $(0.03 \%$ of emissions at most) and the market participation has been broad (Farrell, 2002; U.S. EPA, 2002). Attainment of the environmental objective is far from certain, but this due to the spatial and temporal nature of the pollutant: ozone is transported from uncovered "upwind" states to covered "downwind" states, and the capacity of the program to properly deal with "temporal hot spots" (ozone pollution peaks) is an open question. In any case these issues do not apply to GHGs.

Some features of the EU directive proposal are more harmonised: sanctions are common and so are participants since there is no opt-in possibility at the moment. As in the OTC system, in the first period, states have a large degree of freedom to set their allocation rule provided this allocation is for free.

However a key difference is that the OTC budget program sets an overall cap for each state whereas in the EU proposal, the overall cap for each Member State will be defined by the national allocation plan submitted by this State and reviewed by the European Commission. The EU-wide cap will then result from the addition of these national caps. The Commission can reject proposed plans, but this would probably lead to difficult political disputes. As a consequence, in the European proposal, distortion of competition problems could arise not only because the allocation criteria are not precise enough (cf. section 2.3 above), but also because the total amount of allowances to be distributed in each Member State will be decided during the review of national allocation plans, probably without much transparency.

The OTC budget trading program is badly known in Europe, probably because of its novelty and of its complex architecture. However, precisely because of this complex competence sharing between the federal and the state level, a problem which also arises for European directives, Europeans should devote 
prominent attention to this experience as well as to other forthcoming $\mathrm{NO}_{\mathrm{X}}$ trading programs ("SIP Call" and "Federal $\mathrm{NO}_{\mathrm{X}}$ budget"; cf. Farrell and Morgan, 2001).

\section{Conclusion}

A review of the theoretical and applied literature, as well as a systematic comparison of ten existing or proposed trading schemes, allows us to draw two kinds of conclusions: an appraisal of European Commission GHG trading directive proposal, and some reflections on the discrepancy between economic theory and international experience.

The European directive proposal has many good provisions. First it provides a wide spatial and sectoral coverage. Note that the latter could have been narrowed a lot by the opt-out provision - present in previous drafts of the proposal - which allowed a state to exclude some sectors from the system provided that they were regulated by another instrument, such as a voluntary agreement. Such a provision, which is still pushed for by some industries and Member States, may harm a lot the efficiency of the system. Second, concerning temporal flexibility, the directive proposal allows banking but not borrowing. Both provisions seem sound, the former because there is no risk of "temporal hot spot" in the context of climate change, the latter because the resulting loss of cost-effectiveness is a reasonable price to pay for easing enforcement. Third, for the trading organisation, the proposal soundly sticks to usual practices by allowing bilateral transactions without government approval but with mandatory registration.

However other provisions raise some concerns. First, high quality monitoring is deemed essential by the Commission, which motivates its decision to start with the sole $\mathrm{CO}_{2}$. However even for this gas calculation using activity data, emission factor and oxidation factor is not without problems. The accuracy of current national inventories based on this method falls far short of what is needed for a trading scheme, so further guidance has to be provided at the EU level.

Second, although compliance penalties seem to be set at a sufficiently high level, a difficulty may stem from the international character of EU policy: the directive has first to be transposed in Member States legislation and then put 
into practice by national administrations, which creates a risk of imperfect enforcement by Member States on top of the classical risk of non-compliance by polluters.

Permit allocation is the item which is the most open to criticism. First, the directive proposal prevents the Member States from selling the permits in the first period (2005-2007) yet available simulation show that covered industries are likely to see their profits rise if all permits are grandfathered. Second, treatment of new entrants remains unclear in the proposal. If the Commission wants to be consistent with the aim of "levelling the playing field", it should give more attention to this question. Third, on the contrary to the U.S. $\mathrm{NO}_{\mathrm{X}}$ OTC budget program - the only ongoing trading scheme integrating the federal and state levels - the European Commission proposal does not set an overall cap for each state. As a consequence distortion of competition problems could arise not only because the allocation criteria vis-à-vis new entrants are not precise enough but also because the total amount of allowances to be distributed in each Member State will be decided in a highly political process.

In spite of these shortcomings, the European Commission directive proposal is clearly a good system which has more ground in economic literature requirements than most other schemes we have reviewed. Unfortunately the text currently faces major lobbying, especially from Member States whose trading system or proposal is incompatible with the directive proposal, and from parts of industry that oppose trading or claim for more flexibility. The risk is high that the proposal be blocked or further watered down.

What main stylised facts emerge regarding the discrepancies between theory and practice? First, sectoral coverage is generally much narrower than expected, mainly for political reasons, i.e., preventing too large an opposition front to materialize. For example in the U.K., since GHG control already faces an opposition from industry, the government has preferred not to include electricity generation in the trading scheme to prevent an increase in households electricity bill. Second, allocation choices clearly reflect political economy considerations, i.e., alleviating opposition from regulated industry, over requirements from economic literature. Third, penalties differ very much among reviewed schemes and compliance appears to be correlated both to the level and to the automatic or case-by-case application of penalties.

Unsurprisingly, these three items - sectoral coverage, allocation and penalties - are the most highly debated in the ongoing negotiation of the European GHG trading directive, and the outcome of this process will determine both the environmental effectiveness and the economic efficiency of the final text. 


\section{Acknowledgements}

The authors gratefully acknowledge useful comments from several anonymous referees, partners from the Interact European project, participants at the CIRED and CERNA seminars and at the $1^{\text {st }}$ CATEP workshop. We also thank the European Commission (DG RTD) and the Institut français de l'énergie for financial support. The usual disclaimer applies.

\section{References}

Babiker, M, L. Viguier, J. Reilly, D. Ellerman and P. Criqui, 2001. The welfare costs of hybrid carbon policies in the European Union, MIT Global Change Report 74

Boom, J.-T. and A. Nentjes, 2002. Alternative design options for emissions trading: a survey and assessment of the literature, Presented at the $2^{\text {nd }}$ CATEP workshop: "Design and integration of national tradable permit schemes for environmental protection", University College London, March 25-26

Bovenberg, L. and L. Goulder, 2000. Neutralising the adverse industry impacts of $\mathrm{CO}_{2}$ abatement policies: What does it cost?, Fondazione Eni Enrico Mattei Working Paper 68.2000

Burtraw, D., K. Palmer, R. Bharvirkar and A. Paul, 2001. The effect of allowance allocation on the cost of carbon emission trading, RFF Discussion Paper 01-30

Cramton, P. and S. Kerr, 2002. Tradable carbon permit auctions: How and why to auction not grandfather, Energy Policy, 30 (4): 333-345

Edwards, T. H. and J. P. Hutton, 2001. Allocation of carbon permits within a country: a general equilibrium analysis of the United Kingdom, Energy Economics, 23(4): 371-386.

Ellerman A. D., 2001. U.S. country report on emissions trading, Presented at the $1^{\text {st }}$ CATEP meeting, CIRED, Paris, May 14 
Environmental Law Institute, 1997. Implementing an Emissions Cap and Allowance Trading System for Greenhouse Gases: Lessons from the Acid Rain Program, $71 \mathrm{p}$.

Ermoliev, Y., M. Michalevich and A. Nentjes, 2000. Markets for tradeable emission and ambient permits: a dynamic approach, Environmental and Resource Economics, 15: 39-56

European Commission, 2000. Green Paper on greenhouse gas emission trading within the European Union, doc. COM (2000)87, Brussels

European Commission, 2001a. Proposal for a directive establishing a framework for greenhouse gas emissions trading within the European Community, October 23

European Commission, 2001b. European Climate Change Programme report, June

Farrell, A., 2001. Multi-lateral emission trading: lessons from inter-state $\mathrm{NO}_{\mathrm{X}}$ control in the United States, Energy Policy, 29: 1061-72

Farrell, A., 2002. $\mathrm{NO}_{X}$ emission trading in the Northeast: Trends and outlook, Presented at the NETL SCR-SNCR Conference, May, Pittsburgh, PA

Farrell, A., R. Carter and R. Raufer, 1999. The $\mathrm{NO}_{\mathrm{x}}$ Budget: market-based control of tropospheric ozone in the north-eastern United-States, Resources and Energy Economics, 21: 103-124.

Farrell, A. and M. G. Morgan, 2001. Multi-lateral emission trading: Implications for international efforts from two U.S. examples, Carnegie Mellon Electricity Industry Center, CEIC working paper 01-02

Fischer, C., 2001. Rebating environmental policy revenues: Output-based allocations and tradable performance standards, Resources for the Future Discussion paper 01-22.

Fouquin, M., K. Sekkat, J. Mansour, N. Mulder and L. Nayman, 2001. Sector Sensitivity to Exchange Rate Fluctuations, CEPII working paper, 11, CEPII, Paris, November

Fullerton, D. and G. Metcalf, 2001. Environmental controls, scarcity rents, and pre-existing distortions, Journal of Public Economics, 80: 249-67.

Glachant, M. ed., 2001. Implementing European environmental policy: The impacts of directives in the Member States, Edward Elgar, U.K. 
Goulder, L., 1995. Environmental Taxation and the Double Dividend: A Reader's Guide, International Tax and Public Finance, 2(2): 157-183.

Goulder L, I. Parry, R. Williams and D. Burtraw, 1999. The cost-effectiveness of alternative instruments for environmental protection in a second-best setting, Journal of Public Economics, (72)3: 329-360

Haites, E. and F. Missfeldt, 2000. Costs and environmental impacts of liability proposals, Report prepared for EPRI, Palo Alto, CA

Hahn, R. W., 1984. Market Power and Transferable Property Rights, The Quarterly Journal of Economics, 398(4), 753-765.

Harrison, D. and D. B. Radov, 2002. Evaluation of alternative initial allocation mechanisms in a European Union greenhouse gas emissions allowance trading scheme, National Economic Research Associates for the European Commission (DG Environment)

Hourcade, J.-C. and P. Quirion, with F. Ghersi, K. Helioui and A. Seiler, 2002. Unequal Carbon Constraints and International Competition: A Real Issue?, Presented at the $19^{\text {th }}$ MIT Global Change Forum, Paris, June 12-14

Howe, C. W., 1994. Taxes versus Tradable Discharge Permits: a Review in the Light of the U.S. and European Experience, Environmental and Resource Economics, 4(2): 151-169

Kehoane, N., R. Revesz and R. Stavins, 1998. The positive political economy of instrument choice in environmental policy, in P. Portney and R. Schwab, eds., Environmental economics and public policy, Edward Elgar, London

Klemperer, P., 1999. Auction theory: A guide to the literature, Journal of economic surveys, 13(3): 227-86

Kopp, R. et al., 1999. Domestic early action: a mandatory, comprehensive permit trading system, mimeo, Resources for the Future, Washington DC.

Laan, R. van der and A. Nentjes, 2001. Competitive distortions in EU environmental legislations: inefficiency versus inequity, European Journal of Law and Economics, 11(2): 131-152

Milliman, S. R. and R. Prince, 1989. Firm incentives to promote technological change in pollution control, Journal of Environmental Economics and Management, 17: 247-265 
Misiolek W. S. and H. W. Elder, 1989. Exclusionary Manipulation of Markets for Pollution Rights, Journal of Environmental Economics and Management, 16: $156-166$

Montero J. P., 2000. Optimal Design of a Phase-in Emissions Trading Program, Journal of Public Economics 75(2): 273-291

Rosenzweig, R., M. Varilek and J. Janssen, (2002). The emerging international greenhouse gas market, PEW Center on Global Climate Change

Rubin, J., (1996). "A Model of Intertemporal Emission Trading, Banking and Borrowing.", Journal of Environmental Economics and Management 31(3): 269-286

Schwarze, R. and P. Zapfel, (2000),. Sulphur allowance trading and the regional clean air incentives market: A comparative design analysis of two major cap-and-trade permit programs, Environmental and Resource Economics, $17,:$ 279-98

Sonneborn, C., 1999. An overview of greenhouse gas emissions trading pilot schemes and activities, Ecological Economics, 31: 1-10

Stavins R. N., 2001. Experience with market-based environmental policy instruments, Resources for the Future Discussion Paper 01-58, Washington D.CPotters J. and F. van Winden (1996) "Models of interest groups: four different approaches", in N. Schofield ed. Collective decision-making: Social choice and political economy, Kuwer, pp. 337-362

Stranlund, J. K., C. A. Chavez and B. C. Field, 2002. Enforcing emission trading programs: Theory, practice, and performance, Presented at the $2^{\text {nd }}$ CATEP workshop: "Design and integration of national tradable permit schemes for environmental protection", University College London, March 25-26

Tietenberg, T. 1998. Ethical influences on the evolution of the U.S. tradable permit approach to air pollution control, Ecological Economics (24)2-3: 241257

Tietenberg, T. 1999a. Editor's Introduction in The Evolution of Emission trading: Theoretical Foundations and Design Considerations.

Tietenberg, T., 1999b. Tradable Permit Approaches to Pollution Control: Faustian Bargain or Paradise Regained?, in: M.D. Kaplowitz, Property Rights, Economics, and the Environment, JAI Press Inc. Stamford, CT 
Tietenberg, T. (2000), Economic instruments for pollution control when location matters: What Have We Learned?, Environmental and Resource Economics, 5, 95-113

Tietenberg, T., (2001),. The Tradable Permits Approach to Protecting The Commons: What Have We Learned?, Presented at the $1^{\text {st }}$ CATEP Conference: "Trading scales: Linking industry, local/regional, national and international emission trading schemes", Fondazione Eni Enrico Mattei, Venice, 3-4 December

USU.S. Congressional Budget Office, (2000). Who gains and who pays under carbon allowance trading? The distributional effects of alternative policy designs, Washington DC, June

U.S. EPA, 2002. 2001 OTC $\mathrm{NO}_{X}$ Budget Program Compliance Report, Washington D.C.

Unctad, (1998),. Greenhouse Gas Emission trading - defining the principles, modalities, rules and guidelines for verification, reporting and accountability.

Woerdman E., 2001. Developing a European Carbon Trading Market: Will permit allocation distort competition and lead to state aid?, Fondazione Eni Enrico Mattei working paper 51.01

Zhang Z.X., 1998. Greenhouse gas emissions trading and the world trading system, Journal of World Trade, 32(5): 1-22

Zhang Z.X., 1999a. Should the rules of allocating emissions permits be harmonized?, Ecological Economics, 31: 11-18

Zhang Z.X., 1999b., International greenhouse gas emissions trading: who should be held liable for the non-compliance by sellers?, Ecological Economics (31)3: 323-329 